\title{
Pulmonary Atresia with Bronchial Arteries Arising from the Subclavian Arteries
}

\author{
M. J. TYNAN AND J. A. GLEESON \\ From the Departments of Paediatrics and Radiology, Westminster Hospital, London S.W.I
}

Pulmonary atresia may occur with a normal or an abnormal aortic root; in either case the presence of a collateral circulation to the lungs is obligatory for survival. This may be via a patent ductus arteriosus, if the main branches of the pulmonary artery are developed, by enlarged bronchial arteries anastomosing with the pulmonary artery branches or supplying the lungs direct, or by means of some other systemic pulmonary anastomosis from the aorta or great vessels.

\section{Case Report}

J.C. was the second-born child, the previous child being alive and well. The pregnancy was complicated by mild upper respiratory infections at 5 and at 30 weeks. No drugs were taken during the pregnancy. The baby was born at term, weighing $7 \mathrm{lb}$. (3175 g.); she appeared well at birth.

A cardiac murmur was heard at 1 week of age. At the age of 3 weeks she had an illness characterized by a hæmorrhage from the umbilicus, anorexia, and dyspnœa; this resolved spontaneously after a few days. At 5 weeks she began to have cyanotic attacks, and during the most severe of these she became apnœic.

At 8 weeks she was seen at the Westminster Hospital. She had central cyanosis, but was well developed. Only one component of the second heart sound was heard. There was a loud pansystolic murmur over the whole præcordium, maximal in the second, third, and fourth intercostal spaces at the left sternal border. A continuous systolic and diastolic murmur, suggesting a patent ductus arteriosus, was heard just below the left clavicle. A chest radiograph showed right-sided cardiac enlargement, pulmonary oligæmia, and appearances suggesting bronchial artery circulation to the lungs. The electrocardiogram was normal.

At 12 weeks she was admitted to the Westminster Hospital for investigation. In addition to the physical signs noted previously the continuous murmur was now audible posteriorly, in both mid and lower zones, maximal on the right.

Cardiac catheterization revealed that both ventricles emptied into the aorta; no pulmonary artery was demon- strated. Two-plane selective angiocardiography was carried out with injection into the anterior ventricle of $8 \mathrm{ml}$. of 65 per cent Hypaque by means of a hand-pump (Westminster type). Films were taken at 8 frames per second for 2 seconds, the rest at 4 frames per second (Fig. 1, 2, and 3).

The right ventricle was thick walled with well-marked trabeculation. No pulmonary artery was demonstrated. Most of the contrast medium passed into a large aorta which ran upwards and to the left. The left ventricle was small, and there was a high ventricular septal defect. The coronaries and the great vessels arising from the arch appeared normal, but a large vessel was seen running downwards medially from the first part of each subclavian to behind the cardiac shadow. The peripheral pulmonary vessels were small and suggestive of enlarged bronchial arteries.

At 14 weeks of age a thoracotomy was performed by Mr. C. E. Drew with the object of ascertaining whether the pulmonary artery, if present, could be dilated. At operation there was found to be no pulmonary artery, only a fibrous cord arising from the right ventricle. No operative measures were possible. During the postoperative period she had frequent paroxysmal arrhythmias including ventricular tachycardia. She died 36 hours after operation.

Necropsy. The abnormal findings were confined to the cardiovascular system (Fig. 4 and 5).

The heart was only slightly enlarged. The venous connexions were normal. Both atria and atrio-ventricular valves were normal. The right ventricle was slightly dilated and moderately hypertrophied. A single vessel, guarded by three valve cusps, arose from it and arched to the left to form the aorta.

The coronary, innominate, left common carotid, and left subclavian arteries arose normally from the aorta. There was no recognizable pulmonary artery, but a thin fibrous cord arose from the anterior aspect of the right ventricle and passed in front of the single arterial trunk to the hilum of the left lung. The left ventricle was small. There was a ventricular septal defect $0.8 \mathrm{~cm}$. in diameter in the upper part of the septum. The aorta did not appear to be overriding.

From the first part of the right subclavian artery a 


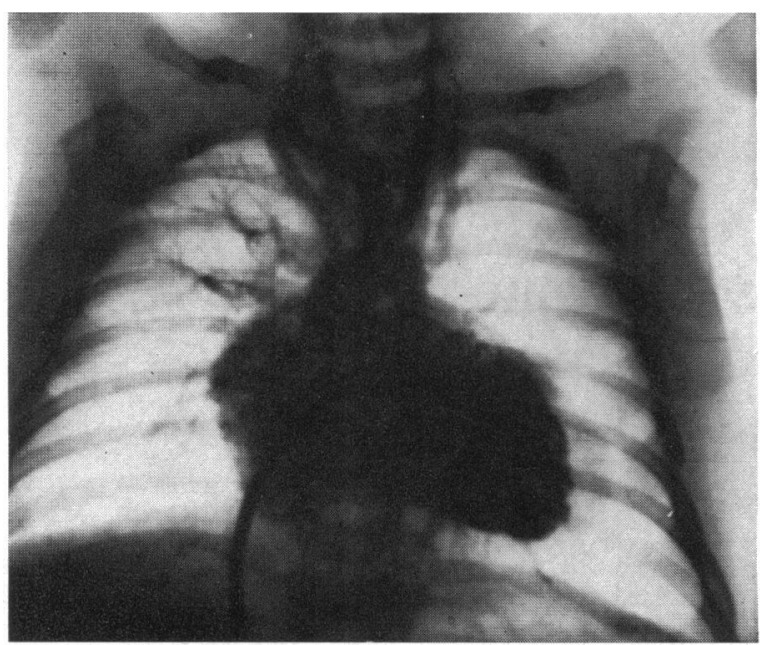

FIG. 1.-Antero-posterior angiocardiogram, with catheter in the anterior ventricle.

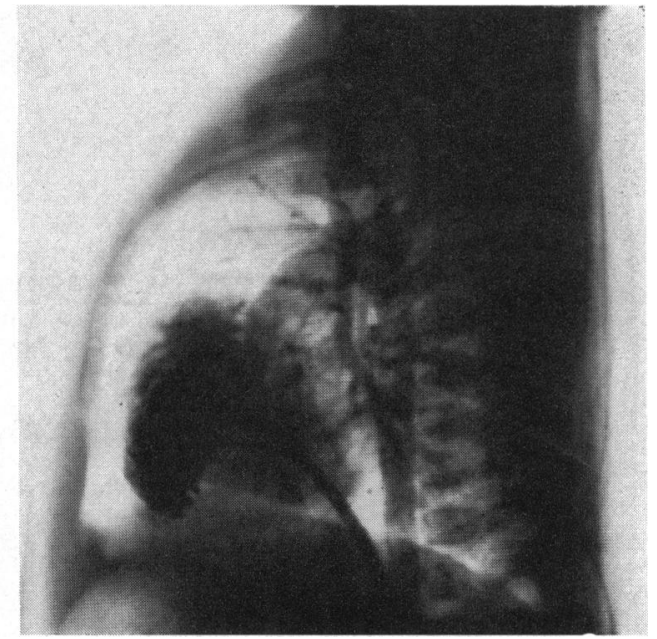

FIG. 2.-Lateral angiocardiogram.

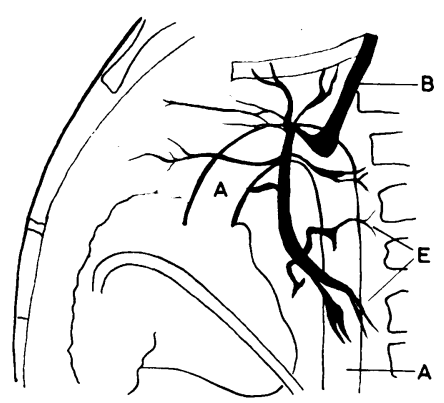

FIG. 3.-Key to the angiocardiograms. (A) aorta; (B) anomalous bronchial arteries; (C) subclavian arteries; (D) vertebral arteries; (E) collateral pulmonary circulation.

moderate-sized vessel arose, which passed posteriorly and downwards to gain the antero-lateral aspect of the right main bronchus, entering the hilum of the lung anterior to the bronchi to supply the right upper and middle lobes. From the first part of the left subclavian artery a similar, but smaller, vessel arose. This arched upwards for a short distance, then passed posteriorly and downwards to the carina which it crossed anteriorly from left to right to gain the antero-medial aspect of the right main bronchus. It then entered the hilum anterior to the lower lobe bronchus to supply the right lower lobe.

The left lung was supplied by 2 bronchial arteries arising by a common origin from the ventral aspect of the descending aorta $3 \mathrm{~cm}$. below the origin of the left subclavian artery.

\section{Discussion}

There are few published reports of bronchial arteries arising from the subclavians. O'Rahilly,
Debson, and King (1950) could only find 12 cases to add to their one, though in a series of 150 necropsies, Cauldwell et al. (1948) found an incidence of 2 per cent. In association with pulmonary atresia, 3 further cases have been recorded (Allanby et al., 1950; Campbell and Gardner, 1950; Lamers and Bruins, 1958).

In the present case the diagnosis of pulmonary atresia and ventricular septal defect was made in preference to persistent truncus arteriosus because of the presence of a fibrous cord in the position usually occupied by the pulmonary artery, together with the absence of any recognizable pulmonary artery elements. The fact that the aorta appeared to arise solely from the right ventricle suggests that this may be a variant of the double outflow right ventricle. 


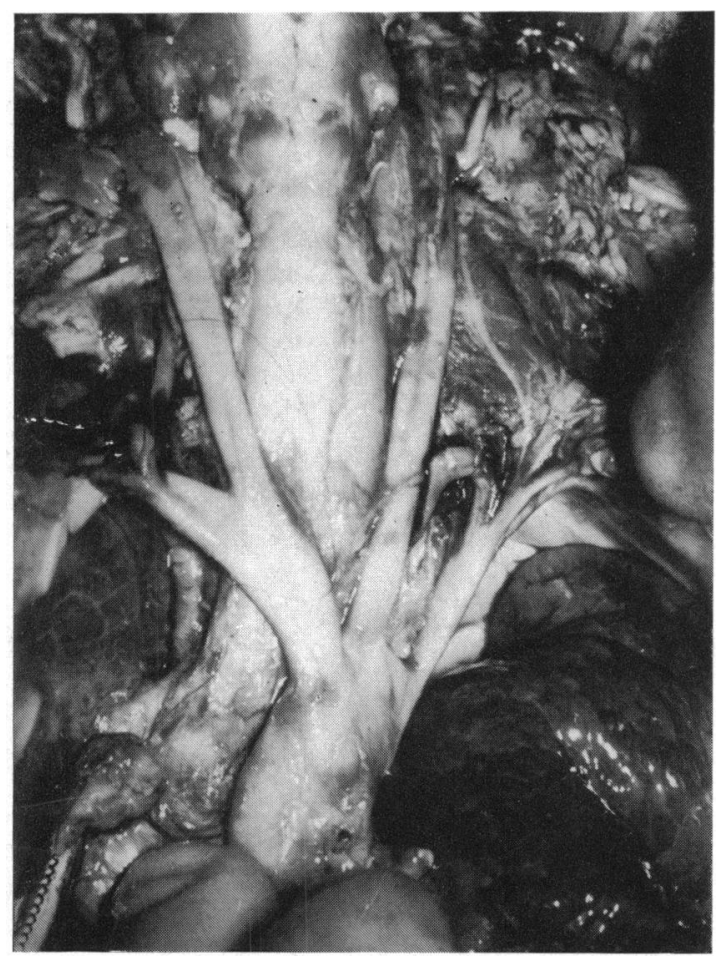

The lungs received the whole of their blood supply via collateral vessels. The bronchial arteries to the left lung arose in a normal manner. The bronchial artery from the right subclavian to the right upper and middle lobes had an origin, course, and distribution similar to that described by Cauldwell et al. (1948), though no middle lobe branch was described in their case.

O'Rahilly et al. (1950) described a bronchial artery arising from the left subclavian and supplying the lower lobes of both lungs, passing anterior to the carina and entering the right lower lobe on the antero-medial aspect of the bronchus. The course of the vessel arising from the left subclavian in the present case is similar to this, apart from the absence of a branch to the left lung.

No concrete information is available on the embryology of the bronchial arteries, though Huntington (1919) inferred that persistence of the aortic radicals of the post-branchial pulmonary plexus, after union of that plexus with the 6th arch, might be the origin of the bronchial arteries. Huntington's observations were not entirely confirmed by Congdon (1922). The frequency with which the bronchials take origin from the intercostal arteries, and in some cases the subclavians, suggests that they arise in close proximity to the developing segmental arteries and may take secondary origin from

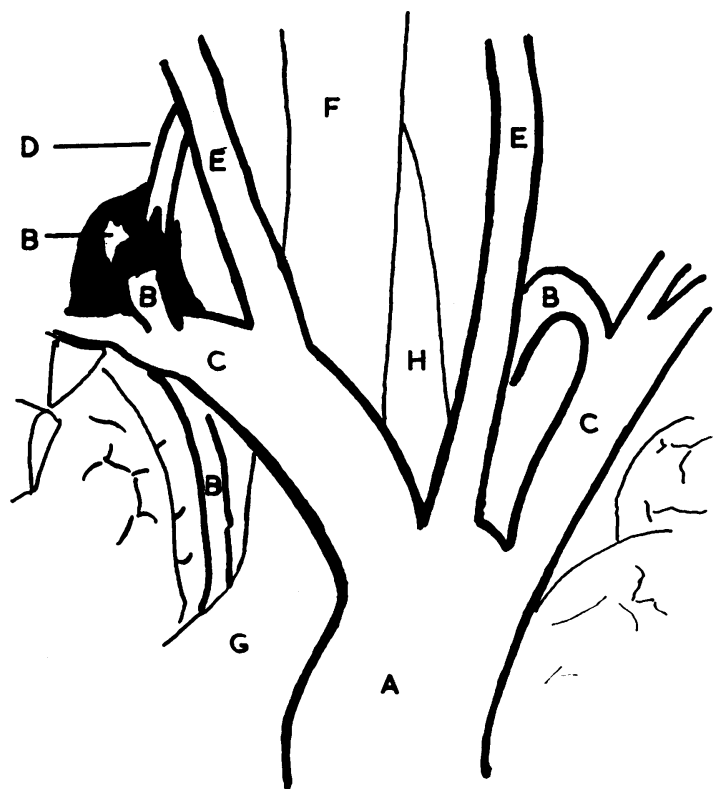

FIG. 4.-Necropsy, appearance of the great vessels in situ. (A) aorta; (B) anomalous bronchial arteries; (C) subclavian arteries; (D) right vertebral artery; (E) common carotid arteries; (F) trachea; (G) right main bronchus; (H) oesophagus.

them through existing anastomosis during the descent of the heart into the thorax.

In addition to demonstrating the origins of the bronchial arteries, Cauldwell et al. (1948) have shown extensive small anastomotic channels between the bronchial arteries and both internal mammaries and the right subclavian.

Allanby et al. (1950), in one of their cases of pulmonary atresia, demonstrated a collateral circulation derived from multiple small vessels arising from the aorta and its branches, including the left subclavian, which freely anastomosed together before supplying both lungs.

There are thus many potential channels through which a systemic blood supply to the lungs may be developed both in foetal and extrauterine life. In the present case the absence of any alternative pulmonary blood supply, together with the early appearance of a bronchial artery murmur, make it probable that the collateral circulation was established at the time of failure of the 6th arch development rather than in the postnatal period (Wagenvoort, Heath, and Edwards, 1964).

\section{Summary}

A case of pulmonary atresia and ventricular septal defect with subclavian origin of the bronchial arteries to the right lung has been described. 


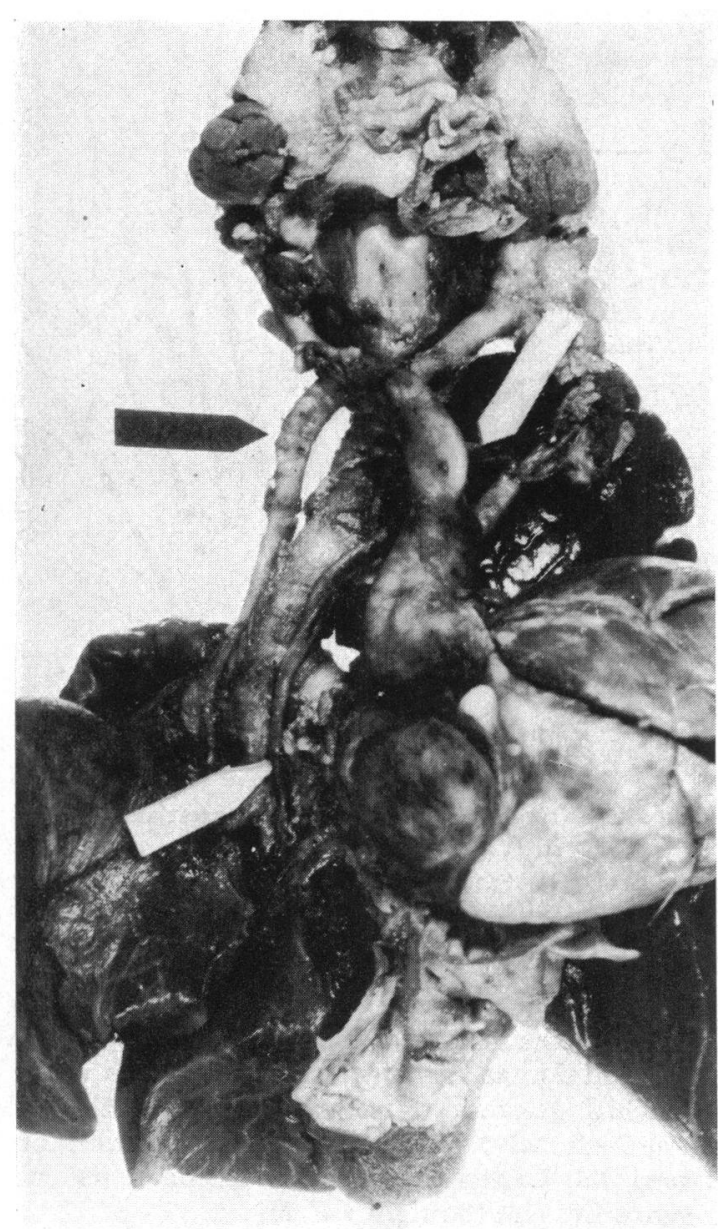

The development of the collateral circulation to the lungs has been discussed. It is suggested that this was established at the time of failure of 6 th arch development.

We wish to thank Dr. I. M. Anderson for permission to present this case and for his help in the preparation of the paper.

We would also like to thank Mr. C. E. Drew, who performed the operation, Dr. I. M. P. Dawson who performed the necropsy, Dr. Basil Strickland for allowing us to use the angiocardiograms, and Dr. P. Hansell for the photography.

\section{References}

Allanby, K. D., Brinton, W. D., Campbell, M., and Gardner, F. (1950). Pulmonary atresia and the collateral circulation to the lungs. Guy's Hosp. Rep., 99, 110.

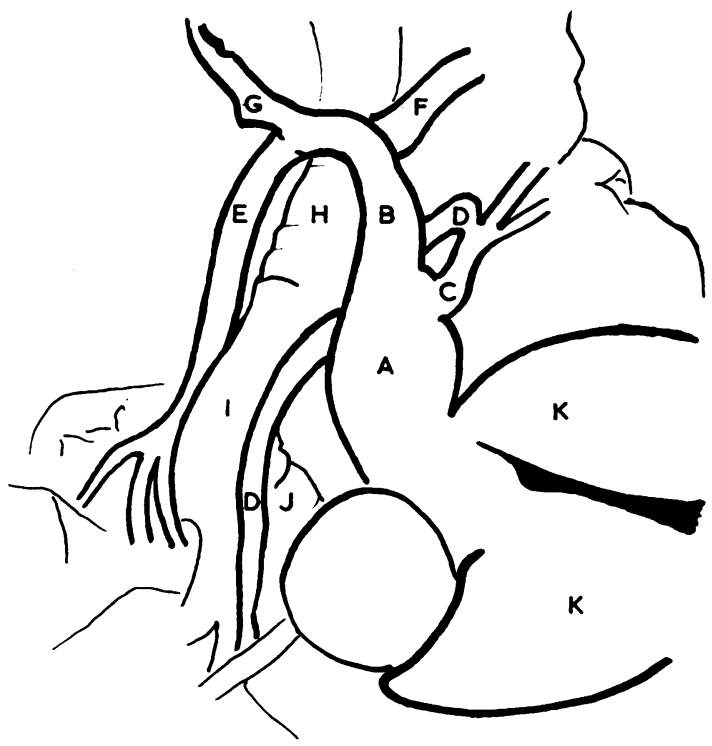

FIG. 5.-Necropsy specimen displayed to demonstrate the course of the anomalous bronchial arteries. The one arising from the left subclavian, indicated by the white arrows, crossing the mid line to enter the right lower lobe. The one arising on the right, shown by the black arrow, passing down to supply the right upper lobe.

(A) Aorta; (B) innominate artery; (C) left subclavian artery; (D) bronchial artery arising from the left subclavian; (E) bronchial artery arising from the right subclavian; (F) left common carotid; (G) right common carotid; (H) trachea; (I) right main bronchus; (J) left main bronchus; (K) heart, retracted to the left.

Campbell, M., and Gardner, F. (1950). Radiological features of enlarged bronchial arteries. Brit. Heart $\mathcal{F} ., 12,183$.

Cauldwell, E. W., Siekert, R. G., Lininger, R. E., and Anson, B. J. (1948). The bronchial arteries. An anatomic study of 150 human cadavers. Surg. Gynec. Obstet., 86, 395.

Congdon, E. D. (1922). Transformation of the aortic-arch system during the development of the human embryo. Contr. Embryol. Carneg. Instn, 14, 47 [No. 68].

Huntington, G. S. (1919). The morphology of the pulmonary artery in the mammalia. Anat. Rec., 17 (Dec.), p. 165.

Lamers, J. J. H., and Bruins, C. (1958). Thoracic aortography in atresia of the pulmonary artery. Arch. chir. neerl., 10, 386.

O'Rahilly, R., Debson, H., and King, T. S. (1950). Subclavian origin of bronchial arteries. Anat. Rec., 108, 227.

Wagenvoort, C. A., Heath, D., and Edwards, J. E. (1964). The Pathology of the Pulmonary Vasculature. Charles C. Thomas, Springfield, Illinois. 